\title{
In vitro methods for generating highly purified EBV associated tumor antigen-specific $T$ cells by using solid phase $T$ cell selection system for immunotherapy
}

\author{
Jongming Li \\ Thomas Jefferson University \\ Bijoyesh Mookerjee \\ Thomas Jefferson University \\ John Wagner \\ Thomas Jefferson University \\ Neal Flomenberg

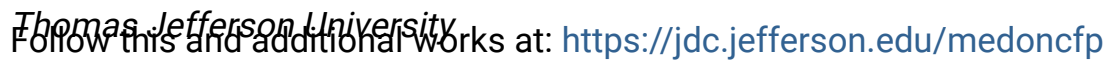 \\ Part of the Medical Immunology Commons \\ Let us know how access to this document benefits you
}

\section{Recommended Citation}

Li, Jongming; Mookerjee, Bijoyesh; Wagner, John; and Flomenberg, Neal, "In vitro methods for generating highly purified EBV associated tumor antigen-specific T cells by using solid phase $T$ cell selection system for immunotherapy" (2007). Department of Medical Oncology Faculty Papers. Paper 1.

https://jdc.jefferson.edu/medoncfp/1

This Article is brought to you for free and open access by the Jefferson Digital Commons. The Jefferson Digital Commons is a service of Thomas Jefferson University's Center for Teaching and Learning (CTL). The Commons is a showcase for Jefferson books and journals, peer-reviewed scholarly publications, unique historical collections from the University archives, and teaching tools. The Jefferson Digital Commons allows researchers and interested readers anywhere in the world to learn about and keep up to date with Jefferson scholarship. This article has been accepted for inclusion in Department of Medical Oncology Faculty Papers by an authorized administrator of the Jefferson Digital Commons. For more information, please contact: JeffersonDigitalCommons@jefferson.edu. 


\title{
In vitro methods for generating highly purified EBV associated tumor antigen-specific $T$ cells by using solid phase $\mathbf{T}$ cell selection system for immunotherapy
}

\section{RUNNING TITLE:}

Tumor Antigen-Specific T cell Selection and Expansion

\author{
AUTHORS: \\ Jongming Li*, Bijoyesh Mookerjee*, John Wagner*, Neal Flomenberg*. \\ *Department of Medical Oncology, 1024 Curtis Building, Thomas Jefferson University, 1015 \\ Walnut St., Philadelphia, PA, USA 19107 \\ Abstract word count: 211 words \\ Text word count: 5653 words \\ Number of Figures: 4 \\ Key words: LMP2-specific T cells, Cell immobilization, T cell selection.
}

\begin{abstract}
Adoptive cell transfer immunotherapy has been utilized to treat EBV related human malignancies including post-transplant lymphoproliferative diseases, Hodgkin lymphoma and nasopharyngeal carcinoma. However, there are limited options available for tumor antigen-specific $\mathrm{T}$ cell purification. Here we describe a novel solid phase T cell selection system, in which monocytes or EBV transformed B-lymphocytes are immobilized on solid support for antigen-specific $\mathrm{T}$ cell purification. We hypothesize and prove that antigen-specific $\mathrm{T}$ cells recognize their cognate antigens and bind to them faster than non-antigen specific $\mathrm{T}$ cells. Therefore antigen-specific $\mathrm{T}$ cells can be concentrated on the surface after removing the non-adherent cells by washing. Optimal selection time for both EBV-specific T cells and LMP2-specific T cells are studied. Our data demonstrated that frequency of antigen-specific $\mathrm{T}$ cells can be increased by $>20$-fold after selection. Moreover, activated antigen-specific $\mathrm{T}$ cells proliferate more rapidly than non-specific $\mathrm{T}$ cells, further increasing the frequency and purity of antigen-specific $\mathrm{T}$ cells. This new $\mathrm{T}$ cell selection system is superior to traditional repeated stimulation methods in generating tumor antigen-specific T cells. Particularly, we are able to generate large quantity of highly purified T
\end{abstract}


cells of subdominant antigens LMP2 within 2 weeks after T cell activation for adoptive cell transfer immunotherapy with his simple, rapid and inexpensive T cell selection system.

\section{Introduction}

Epstein-Barr virus (EBV) is associated with several human malignancies including Burkitt's lymphoma, EBV-associated post-transplant lymphoproliferative diseases (PTLD), Hodgkin lymphoma (HL) and nasopharyngeal carcinoma (NPC). The cells of these tumors express a range of EBV latent gene products that have made them potential targets for T cell-mediated immunological therapies. Adoptive cell transfer (ACT) immunotherapy is based on the ex vivo selection of tumor-reactive lymphocytes, their activation and numerical expansion before reinfusion to the autologous tumor-bearing host. ACT immunotherapy has successfully prevented and treated PTLD occurring after hematopoietic stem cell and solid organ transplants (Rooney et al., 1995; Heslop et al., 1996; Rooney et al., 1998; Khanna et al., 1999; Gustafsson et al., 2000). In addition, Results from several clinical trials have proved autologous EBV-targeted T cells infusions effective in promoting clinical tumor response, including clinical remissions in some instances in patients with HL and NPC (Bollard et al., 2004a; Straathof et al., 2005; Bollard et al. 2004b; Comoli et al., 2005). In these clinical trials, EBV-specific cytotoxic T lymphocytes (CTLs) are generated with peripheral blood mononuclear cells (PBMC) by repeated stimulation using patient-derived EBV transformed B lymphocyte (LCL) as antigen presenting cells. Unfortunately, LCL expresses complete range (latency III) of EBV latency genes: Epstein-Barr nuclear antigens (EBNAs) 1, 2, 3 (3A, 3B, 3C), EBNA-LP and the latent membrane proteins (LMP) 1 and 2, whereas EBV-associated HL and NPC tumor cells display limited (latency II) gene expression, in which EBV latent gene expression is restricted to the EBNA1, LMP1 and LMP2 proteins (Young et al., 1988; Fahraeus et al., 1988; Pallesen et al., 1991; Brooks et al., 1992; Deacon et al., 1993; Grasser et al., 1994; Niedobitek et al., 1997). Furthermore, not only can it take several months to engineer EBV-specific cytotoxic T cells in sufficient quantity and 
quality, but also there is very low frequency of tumor antigen-specific T cells (e.g. LMP2-specific T cells) in the final products. A major challenge to the development of ACT immunotherapy remains the need to produce tumor antigen-specific $\mathrm{T}$ cells not only in large quantity and high purity, but also inexpensively, simply and rapidly.

Activation of $\mathrm{T}$ lymphocytes is mediated by the interaction of $\mathrm{T}$ cell antigen receptors (TcRs) with their ligands, major histocompatibility molecule-peptide complexes (MHC-peptide) through multiple stages (Grakoui et al., 1999). The initial molecular pattern as the consequences of TCR engagement with MHC-peptide can be described as an immature immunological synapse in which the TcR is engaged in the periphery of the extensive contact area. This is followed by formation of a mature immunological synapse in which the TcR is clustered in the center of the contact area over a period of hours (Monks et al., 1998; Grakoui et al., 1999). Full T cell activation leading to proliferation demands sustained TcR engagement and signaling that requires many minutes or hours (Lezzi et al., 1998). Thus the interval between initiation of the immunological synapse formation and $\mathrm{T}$ cell proliferation makes it possible to select antigenspecific $\mathrm{T}$ cells by antigen presenting cells that are attached to a solid support, whereas the nonadherent cells can be removed by washing. The underlying hypothesis of our novel $\mathrm{T}$ cell purification method is that: $1^{\text {st }}$, antigen-specific T cells recognize their cognate antigens and bind to them faster than non-antigen specific $\mathrm{T}$ cells; $2^{\text {nd }}$, activated antigen-specific $\mathrm{T}$ cells proliferate more rapidly than non-specific T cells. Among the choices of antigen presenting cells, both monocytes and LCL are readily available and can present antigens for T cell selection. While monocytes adhere to solid support spontaneously, LCL is non-adherent. To develop our solid phase T cell selection system, we synthesized an activated polyethylene glycol (PEG) polymer (2O-4,6-dichloro-s-triazine-polyethylene glycol-2-O-4,6-dichloro-s-triazine) to immobilize nonadherent antigen presenting cells including LCL onto support surface. 


\section{Materials and Methods}

\section{Study population}

PBMC was collected by apheresis from paid healthy donors at Thomas Jefferson University.

Lymphocytes and monocytes that were seperated by Elutra ${ }^{\circledR}$ (Gambro) were processed by FicollHypaque, frozen and stored in liquid nitrogen until use. This study has been reviewed and approved by IRB at Thomas Jefferson University.

\section{Peptides}

EBV LMP2 epitope peptides LLWTLVVLL (LLW), CLGGLLTMV (CLG), FLYALALLI

(FLY), TVCGGIMFL (TVC) (restricted to HLA-A*0201, >90\% purity) (Straathof et al., 2005)

and Cytomegalovirus (CMV) pp65 peptide $\mathrm{P}_{495-503}$ NLVPMVATV (restricted to HLA-A*0201) were purchased from Biosynthesis Inc.

\section{Preparation of activated PEG polymer}

In a $500 \mathrm{ml}$ round bottom flask containing $150 \mathrm{~mL}$ chloroform, sodium carbonate $(7.066 \mathrm{~g}), 2,4,6-$ trichloro-1,3,5-triazine (2.459g), and PEG600 (4g, all from Sigma-Aldrich) were sequentially added. The mixture was stirred at room temperature for 48 hours, filtered, concentrated in a Rotary Evaporator and dried in vacuum. The final product was stored at $-20^{\circ} \mathrm{C}$ until use.

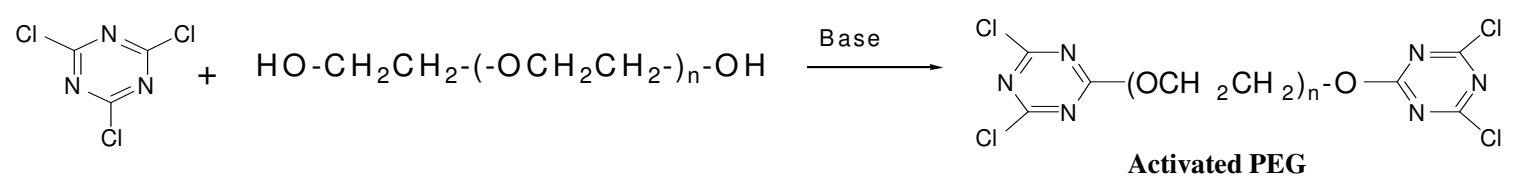

\section{Antigen presenting cell immobilization}

1). Immobilizing LCL on glass through bovine serum albumin (BSA).

A $100 \mathrm{ml}$ Pyrex $®$ glass beaker, which was pre-treated with $20 \%$ sulfuric acid for 4 hours and rinsed in phosphate-buffered saline (PBS), was treated with $3 \mathrm{ml}$ of $5 \%$ bovine serum albumin 
(BSA) for 3 hours at room temperature. After removing BSA solution and rinsing with PBS, $5 \mathrm{ml}$ PBS containing 0.4 gram of activated PEG polymer was added. PH was maintained between 8.5 and 9 (monitored by $\mathrm{pH}$ strips) for 15 minutes at $20-25^{\circ} \mathrm{C}$ by adding sodium bicarbonate solution. After removing the solution, the beaker was rinsed with PBS. $30 \times 10^{6}$ irradiated LCL, which were washed twice with PBS and suspended in $2.5 \mathrm{ml} \mathrm{PBS} \mathrm{(pH8.5),} \mathrm{were} \mathrm{introduced} \mathrm{into} \mathrm{the}$ beaker and were allowed to settle down for 3 minutes. The beaker (covered with a lid from Fisherbrand* Petri Dishes) was moved into the cell culture incubator $\left(37^{\circ} \mathrm{C}\right.$ and $\left.5 \% \mathrm{CO} 2\right)$ without disturbing the precipitated cells for another 20 minutes. Then non-adherent cells were removed and the beaker was gently rinsed with complete medium (RPMI 1640; Mediatech, Inc) containing $10 \%$ human normal AB serum (Gemini), and $2 \mathrm{mM} \mathrm{L-glutamine.} \mathrm{In} \mathrm{general} \mathrm{5 \times 10^{6 }}$ (mean) LCL cells can be immobilized on the surface of $100 \mathrm{ml}$ glass beaker and cell viability (measured by Vi-Cell Counter) is consistently greater than $85 \%$ after immobilization. The immobilized cells were incubated with complete medium in the cell culture incubator for another 60 minutes until use.

2). Immobilizing LCL on glass through covalent binding. A clean, dry $100 \mathrm{ml}$ beaker (treated with sulfuric acid previously) was treated with dilute $(1-4 \%$ in dry acetone) 3-aminopropyltriethoxysilane for about $15 \mathrm{~min}$, rinsed in acetone, water and then followed by the addition of activated PEG polymer solution described above.

3). Immobilizing monocytes in 6-well-plates.

$10 \times 10^{6}$ monocytes were thawed and immediately added to one well of a 6-well-plate (BD Falcon $^{\mathrm{TM}}$ Primaria ${ }^{\circledR}$ ) in $3 \mathrm{~mL}$ of complete medium containing DNAse I (960 U) (Worthington Biochemical Corporation). After 90 minutes in the cell culture incubator, the medium was removed and adherent cells were rinsed with warm $\left(37^{\circ} \mathrm{C}\right) \mathrm{PBS}$, pulsed with $2 \mu \mathrm{M}$ peptide for 90 minutes until use. 


\section{Generation of EBV-transformed B cell lines.}

5-10 $\times 10^{6}$ PBMC was incubated with concentrated supernatant of B95-8 cultures, in the presence of $1 \mu \mathrm{g} / \mathrm{mL}$ cyclosporin A (Sandoz) to establish an LCL.

\section{Generation of EBV-specific CTLs and LMP2-specific CTLs by traditional repeated stimulation method.}

PBMC was co-cultured with irradiated ( $80 \mathrm{~Gy}$ ) autologous LCL or monocytes that were previously pulsed with a LMP2 epitope peptide $(2 \mu \mathrm{M})$ at a responder/stimulator ratio of 10:1. Starting on day 7, the responder cells were re-stimulated with irradiated LCL at a responder/stimulator ratio of $4: 1$ or monocytes pulsed with target peptide at a responder/stimulator ratio 10:1. Two weekly doses of recombinant human IL-2 (rhIL-2) at 20U/ml (Proleukin; Chiron) were added from day 7. On day 14, the responder cells were analyzed by flow cytometric intracellular cytokine assay for IFN- $\gamma$ production.

\section{Antigen-specific T cell selection and expansion (Figure 1)}

PBMC was activated with irradiated LCL or peptide-pulsed-monocytes as described above. On day 7 , activated lymphocytes $\left(90 \times 10^{6} \pm 10\right.$ in $3 \mathrm{~mL}$ complete media, $\left.37^{\circ} \mathrm{C}\right)$ were added onto immobilized antigen presenting cells in cell culture incubator (For LMP2-specific CTLs selection by LCL, LCL was pulsed with $2 \mu \mathrm{M}$ peptide for 4 hours before immobilization. LCL was then irradiated, immobilized and exposed again with CLG for 1 hour; For LMP2-specific CTLs selection by monocytes, peptide treatment of monocyte was described in monocyte immobilization section). Various selection times were tested. Non-adherent cells were removed at the end of each selection time. The remaining adherent cells were gently washed with $37^{\circ} \mathrm{C}$ culture media. Washing was repeated after 30 minutes incubation at $37^{\circ} \mathrm{C}$ because some of nonspecific $\mathrm{T}$ cells selected by antigen presenting cells will disengage and float again. The next day, 
adherent cells were removed by gentle agitation and transferred to a $75 \mathrm{~cm}^{2}$ culture flask $\left(\right.$ Corning $\left.^{\circledR}\right)$ in $100 \mathrm{~mL}$ complete media. RhIL-2 (20U/ml) was added at the time and thereafter every 2-3 days. On day 7 for EBV-specific T cells and day 8 for LMP2-specific T cells, cultured cells were analyzed by ICC with addition of autologous LCL or peptide-pulsed-monocytes as antigen presenting cells.

\section{Intracellular cytokine staining (ICC)}

1). Intracellular IFN- $\gamma$ staining was done as described (Li et al., 2006). Briefly, $2 \times 10^{6}$ lymphocytes were cultured with irradiated autologous LCL (for EBV-specific CTLs, lymphocytes:LCL 1/1) or irradiated peptide-loaded-monocytes (for LMP2-specific CTLs, lymphocytes:monocytes 1/1). After $2 \mathrm{~h}, 10 \mu \mathrm{g} / \mathrm{ml}$ brefeldin A (Sigma) was added and cultures were incubated for a further $4 \mathrm{~h}$. After this period, cells were stained with CD3-PerCP and CD8PE, fixed in FACS Lyse, permeabilized with FACS Perm2 and labelled with anti-IFN-cfluorescein isothiocyanate (all from Becton Dickinson) according to the intracellular-staining procedure protocol supplied by the manufacturer. Immunofluorence measurement were acquired on a FACScalibur flow cytometer and analyzed using CellQuest software. The frequency determined for the unstimulated control was subtracted from the frequency for the LCL or LMP2 peptides-stimulated population to determine the true antigen-specific T-cell frequency.

2). The procedure for intracellular IFN- $\gamma$ staining of selected lymphocytes by immobilized LCL or monocytes on the solid support was modified from the procedure described above. After selecting lymphocytes with immobilized antigen presenting cells, non-adherent cells were removed at the end of each selection time. The remaining adherent cells were gently washed with $37^{\circ} \mathrm{C}$ culture media. Washing was repeated after 30 minutes incubation at $37^{\circ} \mathrm{C}$. At 2 hours after selection, after removing culture media, $6 \mathrm{ml}$ culture media containing $10 \mu \mathrm{g} / \mathrm{ml}$ brefeldin A was 
added and cultures were incubated for a further $4 \mathrm{~h}$. This was then followed by the procedure of cell staining with antibody, lysing and permeation described above.

\section{Tetramer staining}

PE-labeled EBV HLA-A2-tetramer (LMP2 peptide CLGGLLTMV, Beckman Coulter) was used to detect CLG-specific T cells in the CTL lines. PE-labeled M27L HLA-A2-tetramer (Melan-A, 26-35 variant ELAGIGILTV, Beckman Coulter) was used as tetramer control. Tetramer staining was done as described by the manufacturer. Briefly, CTLs $\left(10^{6}\right)$ were incubated at room temperature for 30 minutes in (PBS)/1\% fetal calf serum (FCS) containing the PE-labeled tetrameric complex. Samples were co-stained with anti-CD8 FITC and anti-CD3 PerCP. Stained cells were fixed in PBS containing 0.5\% paraformaldehyde. Cells were acquired on a FACScalibur flow cytometer and analyzed using Cell Quest software.

\section{Chromium Release Assay.}

The cytotoxic specificity of each CTL line was analyzed in a standard 4-h chromium- ${ }^{51}$ release assay (Brunner et al., 1968). The following target cells were tested: autologous LCL; K562, which is sensitive to killing by lymphokine-activated killer cells; and T2 cell line pulsed with CMV peptide as a control for LMP2-specific T cells generated by the solid phase $\mathrm{T}$ cell selection method.

\section{Results}

\section{EBV-specific CTL selection}

One of the most commonly used methods to generate EBV-specific T cells is to stimulate PBMC repeatedly (usually weekly) with autologous LCL. This is followed by T cell expansion in the presence of rhIL-2. In our new T cell purification method we exploited immobilized irradiated 
LCL to select EBV-specific T cells first, followed by T cell expansion. We have performed $\mathrm{T}$ cell selection experiments with PBMC from 3 healthy donors (3 times each for donor 1, 5 and 6). Here we present data from donor 1 (HLA*A0201+) to illustrate the process of T cell selection. General scheme of solid phase T cell selection process was outlined in Figure 1. The mean frequency of EBV-specific CTLs was determined to be $1.8 \%$ by ICC 7 days after PBMC of donor 1 was stimulated with irradiated autologous LCL. To test our first hypothesis, we examined the frequency of EBV-specific T cells selected at various selection times (ranging from 1 to 15 minutes) by immobilized LCL. After non-adherent cells were removed at the end of each selection time, intracellular IFN- $\gamma$ staining of selected lymphocytes on the support surface was performed based on the modified procedure described in Method section. There were $22 \%, 44 \%$, $20 \%, 12 \%$ and $8 \%$ (mean) IFN- $\gamma$ producing cells among cells selected at 1, 3, 5, 10 and 15 minutes, respectively (Figure 2A). Subsequently, we expanded these selected lymphocytes (we did not expand $\mathrm{T}$ cells selected at 1 minute because of the scarcity of selected cells). This was accomplished by adding rhIL-2 $(20 \mathrm{u} / \mathrm{ml})$ one day after selection and then every $2-3$ days thereafter. On day 7, we analyzed these expanded cells by ICC for IFN- $\gamma$ production. IFN- $\gamma$ producing cells were increased to $80 \%, 65 \%, 50 \%$, and $45 \%$ (mean) among the expanded cells of selection times 3, 5, 10 and 15 minutes, respectively (Figure 2B), whereas there were only 15\% (mean) IFN- $\gamma$ producing cells of lymphocytes generated by traditional method (data not shown). There were $30 \times 10^{6}, 100 \times 10^{6}, 120 \times 10^{6}$ and $120 \times 10^{6}$ (mean) cells in final expanded cell population selected at 3, 5, 10 and 15 minutes, respectively. Of cells that were selected from 3 to 5 minutes and expanded for 7 days, $>90 \%$ (mean) of cell population is $\mathrm{CD} 3+\mathrm{CD} 8+$ (data not shown). To test our $2^{\text {nd }}$ hypothesis, we measured the IFN- $\gamma$ production from cells selected at 5 minutes starting right after $\mathrm{T}$ cell selection (day 0), then day 1, 2 and 7 after selection by exposing them to autologous LCL. There were $20 \%, 22 \%, 45 \%$, and $65 \%$ (mean) IFN- $\gamma$ producing cells among cells selected on day 0, 1,2 and 7, respectively (Figure 2D). Of note, there were only 
$0.6 \%$ and $0.8 \%$ IFN- $\gamma$ producing cells in non-stimulated lymphocytes (i.e. negative control) 24 and 48 hours after selection (data not shown). Figure 2E shows that $\mathrm{T}$ cells generated from this new method recognize and kill autologous LCL, whereas there are no significant killings toward K562 and autologous LCL when MHC I antibody (w6/32) was added to the LCL.

Similar patterns were also observed in T cell selection experiments using PBMC from donor 5 and 6 and highest IFN- $\gamma$ production was observed at 3 minutes selection time. In donor 5 and 6 , there were $1.3 \%$ and $1 \%$ of EBV-specific T cells, respectively after PBMC was stimulated with autologous LCL. IFN- $\gamma$ producing cells were increased to $23 \%$ and $30 \%$ (mean) among cells selected at 3 minutes on support surface (data not shown) for donor 5 and 6 , respectively. In donor 5 and 6, we only expanded cells selected at 5 minutes to examine the frequency of EBVspecific $\mathrm{T}$ cells because there was less than desired amount of cells in the final expanded cell population selected from 3 minutes. Right after selection at 5 minutes, there were $20 \%$ and $18 \%$ (mean) IFN- $\gamma$ producing cells among cells on support surface (data not shown) for donor 5 and 6 , respectively. After 7 days expansion, there were $120 \times 10^{6}$ (mean) cells in final expanded cell population for both donors 5 and 6. The percent EBV-specific T cells were increased to $55 \%$ and $50 \%$ (mean) for donor 5 and 6, respectively, whereas there were only $19 \%$ and $12 \%$ (mean) EBVspecific $\mathrm{T}$ cells in lymphocytes generated by traditional method for donor 5 and 6 , respectively (data not shown).

Next we measured the quantities of LMP2-specific T cells in lymphocytes generated from both solid phase $\mathrm{T}$ cell selection method and traditional method. In donor 1, T cell responses to LMP2 epitope peptides LLW, CLG, and FLY were observed. We used autologous monocytes that were pulsed with peptides LLW, CLG, and FLY together as antigen presenting cells to stimulate T cells for IFN- $\gamma$ production. There were $17 \%, 19 \%, 9 \%$ and $7 \%$ (mean) IFN- $\gamma$ producing cells in 
lymphocytes generated from 3, 5, 10 and 15 minutes selection (Figure 2C), whereas there were only $1.2 \%$ (mean) IFN- $\gamma$ producing cells in lymphocytes generated by traditional method (data not shown). In donors 5 and 6 (both are HLA *A0201+), T cell responses to LMP2 epitope peptides LLW, CLG, FLY and TVC were seen. Again we used autologous monocytes that were pulsed with peptides LLW, CLG, FLY and TVC together as antigen presenting cells to stimulate T cells for IFN- $\gamma$ production. Of lymphocytes generated by 5 minutes selection time, there were $16 \%$ and $19 \%$ (mean) IFN- $\gamma$ producing cells for donor 5 and 6 , respectively, whereas there were only $1 \%$ and $0.6 \%$ IFN- $\gamma$ producing cells in lymphocytes generated by traditional method for donor 5 and 6 , respectively (data not shown).

\section{LMP2-specific CTL selection}

We decided to apply our new T cell purification method to select LMP2-specific T cells directly. The general strategy is to activate PBMC with LMP2 epitope peptide-loaded-monocytes first. This would be followed by selection of LMP2-specific T cells with either immobilized autologous LCL or monocytes pulsed with target peptide. Of multiple T cell selection experiments with PBMC from several healthy donors, we present data from donor 5 to illustrate the $\mathrm{T}$ cell selection process. The frequency of CLG-specific $\mathrm{T}$ cells was determined to be $0.8 \%$ (mean) by ICC 7 days after PBMC of donor 5 was stimulated with CLG-loaded-monocytes. First we tested autologous irradiated LCL as antigen presenting cells for CLG-specific T cell selection. We examined various selection times to determine the optimal selection time. After removing non-adherent cells at the end of each selection time, intracellular IFN- $\gamma$ staining of selected lymphocytes on the support surface was performed. IFN- $\gamma$ producing cells were increased to $10 \%$, $17 \%, 24 \%, 21 \%$ and $19 \%$ (mean) among cells selected at 3, 5, 7.5, 10 and 15 minutes, respectively (Figure 3A). Because LCL could also present EBV antigens other than CLG peptide 
and induce IFN- $\gamma$ production among selected T cells, we examined the quantity of IFN- $\gamma$ production that might be contributed by EBV antigens other than CLG. We selected nonstimulated-PBMC with immobilized LCL with selection time of 7.5 minutes and measured the quantity of IFN- $\gamma$ positive cells. There were only $0.4 \%$ (mean) IFN- $\gamma$ positive cells among the selected cells (data not shown). Subsequently, we expanded these selected lymphocytes (we did not expand T cells selected with selection time less than 5 minutes because of the scarcity of selected cells). This was accomplished by adding rhIL-2 (20u/ml) one day after selection and then every 2-3 days thereafter. On day 8 , we analyzed these expanded cells from various selection times by both ICC for IFN- $\gamma$ production and tetramer staining. IFN- $\gamma$ producing cells were increased to 55\%, 70\% and 65\% (mean) among final expanded cells of selection times 5, 7.5 and 10 minutes (Figure 3B), respectively, whereas there were only $12 \%$ IFN- $\gamma$ producing cells of lymphocytes generated by traditional method (data not shown). Tetramer staining yielded $82 \%$ (mean) of CLG-specific T cells among cells generated from 7.5 minutes selection (Figure 3B). CLG-specific T cells generated from this new method lysed T2 cell line pulsed with CLG, whereas there were no significant lysis of $\mathrm{T} 2$ cell line pulsed with CMV peptide $\mathrm{P}_{495-503}$ (Figure 3C). There were $80 \times 10^{6}, 100 \times 10^{6}$ and $100 \times 10^{6}$ (mean) cells in final expanded cell population selected at 5, 7.5 and 10 minutes, respectively. More than $90 \%$ (mean) of these cell populations is $\mathrm{CD} 3+\mathrm{CD} 8+$ (data not shown).

Next, we tested autologous monocytes as antigen presenting cells for CLG-specific T cell selection. Again, we examined various selection times to determine the optimal selection time. After removing non-adherent cells at the end of each selection time, intracellular IFN- $\gamma$ staining of selected lymphocytes on the support surface was performed. IFN- $\gamma$ producing cells were increased to $5 \%, 13 \%, 15 \%, 23 \%$ and $19 \%$ (mean) among cells selected at $1,3,5,7.5$ and 15 minutes, respectively (Figure 4A). Because monocytes could also present antigens other than 
CLG peptide and induce IFN- $\gamma$ production among selected $\mathrm{T}$ cells, we examined the quantity of IFN- $\gamma$ production that might be contributed by antigens other than CLG. There was less than $0.2 \%$ (mean) of IFN- $\gamma$ production when CLG-stimulated-PBMC was selected with immobilized plain monocytes (selection time of 7.5 minutes, data not shown). Subsequently, we expanded these selected lymphocytes (we did not expand T cells selected with selection time less than 5 minutes because of the scarcity of selected cells). This was accomplished by adding rhIL-2 $(20 \mathrm{u} / \mathrm{ml})$ one day after selection and then every 2-3 days thereafter. On day 8 , we analyzed these expanded cells from various selection times by both ICC for IFN- $\gamma$ production and tetramer staining. IFN- $\gamma$ producing cells were increased to $60 \%, 68 \%$ and $45 \%$ (mean) among expanded cells of selection times 5, 7.5 and 15 minutes (Figure 4B), respectively, whereas there were only $12 \%$ IFN- $\gamma$ producing cells of lymphocytes generated by traditional method (data not shown). Tetramer staining yielded 87\% (mean) of CLG-specific T cells among cells generated from 7.5 minutes selection (Figure 4B). CLG-specific T cells generated from this new method lysed T2 cell line pulsed with CLG, whereas there were no significant lysis of T2 cell line pulsed with CMV peptide $\mathrm{P}_{495-503}$ (Figure 4C). There were $40 \times 10^{6}, 80 \times 10^{6}$ and $80 \times 10^{6}$ (mean) cells in final expanded cell population selected at 5, 7.5 and 15 minutes, respectively. More than $90 \%$ (mean) of these cell populations is $\mathrm{CD} 3+\mathrm{CD} 8+$ (data not shown).

\section{Discussion}

In the past two decades, adoptive T cell therapy targeting malignancies such as melanoma and EBV related malignancies has shown promising potential. However, it has been a great challenge to produce functional tumor antigen-specific T cells inexpensively, simply and rapidly. While several approaches to generate tumor-specific CTLs have been successfully introduced in clinical experimental protocols, the establishment of a broadly applicable process is still lacking. There are significant limitations in MHC-tetramer and its related technology such as artificial antigen 
presenting cells. They are costly and limited to a few HLA phenotypes. The IFN- $\gamma$ capture method has been shown to be inefficient and nonspecific in T cell selection. Based on our hypothesis, we have established a simple yet effective antigen-specific T cell selection system. To our best knowledge, this monocyte and LCL based T cell selection system is the first reported so far. However, application of solid phase technology can be dated back to Bruce Merrifield's solid phase peptide synthesis (Merrifield, 1963). In life science, application of solid phase technology is widely seen in almost every fields, involving protein, antibody, DNA and RNA, etc. Data presented here supports our hypothesis that antigen-specific $\mathrm{T}$ cells can be selected by antigen presenting cells preferentially. Moreover, because activated antigen-specific T cells proliferate more rapidly than non-specific $\mathrm{T}$ cells, the final frequency and purity of antigen-specific $\mathrm{T}$ cells can be increased up to $80 \%$ just in 2 weeks, with magnitude of CTLs in the order of $10^{8}$ from each selection and expansion. Shortly after we completed this report, we also completed another report in which we demonstrated that large-scale highly purified Melan-A-specific T cells could be generated with monocyte based solid phase $\mathrm{T}$ cell selection system within 2 weeks after T cell activation. The short time frame required to generate large-scale highly purified tumor reactive $\mathrm{T}$ cells with our method is unprecedented. Of the published clinical trial protocols, it takes a 10-12 week period of in vitro culture with high-dose IL-2 to yield $10^{10}-10^{11}$ tumor-infiltrating lymphocytes (Topalian et al, 1987). This time frame can be cut by half when tumor-infiltrating lymphocytes are expanded using anti-CD3 in combination with irradiated feeder cells to achieve similar numbers (Dudley et al, 2002). Although T cell clones can be expanded over two weeks to achieve numbers $>10^{10}$, there are additional weeks needed to generate the clones first and the cloning process is laborious (Yee et al, 2002). Mackensen and his colleagues (Mackensen et al, 2006) established a protocol to generate M27L-specific T cells by stimulating CD8+ lymphocytes (selected by beads) with dendritic cells weekly for 4 weeks. Of 11 patients treated, there were a total of 52 infusions, with an average of $2 \times 10^{8} \mathrm{M} 27 \mathrm{~L}$-specific T cells in each infusion. As aforementioned, it takes several months to generate adequate amount of EBV-specific T cells by 
protocols of repeated stimulation method for trials in EBV related malignancies. Another important factor regarding ACT is the underlying cost associated with T cell preparation. This becomes particularly important nowadays in the era of targeted cancer therapy, which could exert enormous financial impact on the health care system. For example, the monthly cost of Sorafenib and Sunitinib is about $\$ 8000$ in the United States. Administration of a complete course of Bevacizumab, Herceptin and Cetuximab costs more than one hundred thousand dollors. Relevant to our T cell selection system, the cost of apheresis is about $\$ 500$. The cost of Elutra device is about $\$ 23,000$ and each monocyte elutriation kit is $\sim \$ 1000$. The total cost for each patient (if using monocyte based T cell selection system) is about $\$ 1500+23000 / \mathrm{n}$ ( $\mathrm{n}$ is the total number of patients to be treated). This would be closer to $\$ 1500$ if large number of patients were treated. We believe that our method is superior to the currently known protocols exploited in cancer therapy when considering all critical factors in ACT, i.e. time required for cell production, quantity and quality of cell product, technical difficulty of protocol being used, and cost. It is reasonable to conclude that our method is indeed simple, rapid and relatively inexpensive compared to the published clinical trial protocols.

Of the EBV antigens expressed in EBV-associated HL and NPC tumor cells, namely EBNA1, and latent proteins (LMPs) 1 and 2, processing of EBNA1 through the HLA class I pathway is inhibited by a glycine-alanine repeat. Therefore peptides from EBNA1 are presented to CD8 T cells from incompletely translated proteins (Levitskaya et al., 1995; Voo et al., 2004; Lee et al., 2004; Tellam et al., 2004). This makes EBNA1 a less attractive target for immunotherapy. LMP1 is not an ideal target either, mainly because LMP1 displays heterogeneity between virus strains, so that $\mathrm{T}$ cells raised against B-cell (B95-8 prototype)-derived LMP1 may not recognize the LMP1 tumor variants (Trivedi et al., 1994; Khanim et al., 1996). Epitopes of LMP2, however, are conserved between viral strains (Lee et al., 1993; Busson et al., 1995). Furthermore, the existence of LMP2-specific T cells in patients with HL and NPC have previously been reported (Sing et al., 
1997; Whitney et al., 2002). Therefore the quantity of LMP2-specific T cells might be viewed as the most important element of the final cell culture product for ACT. In this paper, we have demonstrated 2 approaches to produce LMP2-specific T cells. One started with selection of LCL activated EBV-specific T cells. In this approach, the quantities of LMP2-specific T cells represent only minority of EBV-specific T cells, which is consistent with the fact that LMP2 are EBV subdominant antigens. Even so, the quantities of LMP2-specific T cells generated from this new $\mathrm{T}$ cell selection method appears to be much more than that in EBV-specific T cells generated through traditional repeated stimulation method, in which on average only about $1 \%$ of LMP2specific T cells was generated using PBMC from both normal individual and Hodgkin's Lymphoma patients (Bollard et al., 2004b). In patients with known HLA restricted LMP2 epitope peptide, another approach is to select and expand activated LMP2-specific T cells directly. Data presented in this paper demonstrated that our monocyte or LCL based T cell selection system can produce large quantity of high purity LMP2-specific T cells within 2 weeks after $\mathrm{T}$ cell activation. The specificity of these purified LMP2-specific T cells were confirmed by ICC, tetramer staining and cytotoxicity experiments. The discrepancy between the findings of purity of LMP2-specific T cells by ICC and tetramer staining can be attributed to TcR promiscuity. There are several significant clinical implications here. First, very few LMP2specific $\mathrm{T}$ cells can be generated through traditional repeated stimulation method because LMP2 is a subdominant antigen. Moreover, patients with refractory or recurrent HL and NPC usually progress rapidly and may not survive long enough to have their ACT products prepared by traditional repeated stimulation method. Our novel T cell selection system could have immediate therapeutic implications in these patients with refractory or recurrent HL and NPC.

By comparing the selection of EBV-specific T cells and LMP2-specific T cells, it seems that the selection time $\left(\mathrm{T}_{\max }\right)$ at which highest IFN- $\gamma$ positive cells can be generated during $\mathrm{T}$ cell selection is much shorter for EBV-specific T cell selection. There are 2 major factors that may 
play significant roles in regulating $\mathrm{T}_{\max }$. Namely they are the rate of antigen-specific $\mathrm{T}$ cell selection and non-specific T cell selection. Although EBV-specific T cells and LMP2-specific T cells are activated with different antigen presenting cells (i.e. autologous LCL and monocytes, respectively), it is reasonable to assume that those non-specific T cells should possess similar properties in interacting with antigen presenting cells and therefore should display similar selection rates by the same antigen presenting cells. If this assumption holds true, $\mathrm{T}_{\max }$ can be viewed as a surrogate of rate of antigen-specific $\mathrm{T}$ cell selection. In addition, we would like to caution on notions that high avidity $\mathrm{T}$ cells are selected preferentially here. The avidity of the interaction between $\mathrm{T}$ cell and antigen presenting cells is the sum of multiple factors including interactions between TcR and its MHC/peptide ligand, co-receptors, costimulatory and adhesion molecules, as well as signaling machinery and others. It is intuitive to consider that the high avidity $\mathrm{T}$ cells should be selected first with our method. Yet this notion ignores a most important factor in our experiments. That is $\mathrm{T}$ cells, including high and low avidity $\mathrm{T}$ cells, are initially evenly dispersed in media $(3 \mathrm{ml})$ and introduced to antigen presenting cell layer. We observed that it takes at least 5 minutes for $\mathrm{T}$ cells to precipitate and form a uniform layer on top of antigen presenting cell layer. There are no indications which cells, high avidity or low avidity T cells, can precipitate faster to the surface to interact with antigen presenting cells. In addition, our data show that there are significant amount of antigen-specific $\mathrm{T}$ cells that have already been interacting with antigen presenting cells at 1 minutes of co-culturing. We believe that the $\mathrm{T}$ cells selected this way are mostly by chance of their geography, i.e. how close their distance is with antigen presenting cells. T cell avidity, on the other hand, may only play a minor role. Our data here indicate that selection of EBV-specific T cells, in which the majority are $\mathrm{T}$ cells specific for EBV's dominant antigens, is faster than selection of LMP2 (subdominant antigen)-specific T cells. This may partly explain the difference of CTLs responses to EBV's dominant and subdominant antigens since previous studies suggested that the "recruitment time" determined the magnitude of cellular immune response to a particular antigen (Bousso et al., 1999; De Boer et 
al., 2001). In addition, it appeared that there was a significant delay of proliferation for LMP2specific T cells compared to EBV-specific T cells right after T cell selection (unpublished observation). This phenomenon of delayed initiation of cell division of $\mathrm{T}$ cells responding to subdominant antigen was also reported in a previous study (Hommel et al., 2003). Because of delayed proliferation for LMP2-specific T cells, we decided to expand the selected LMP2specific T cells to day 8 instead of day 7 after selection before analyzing their purity and quantity. Clearly these differences between LMP2-specific T cells and EBV-specific T cells merit further studies in the future, particularly in the area of $\mathrm{T}$ cell selection kinetics and proliferation after $\mathrm{T}$ cell activation. In view of these selection kinetic differences between EBV-specific T cells and LMP2-specific T cells, one might raise questions of the optimal selection time for non-EBV related antigen-specific T cells. Moreover, do similar selection kinetic differences exist among T cells of other dominant and subdominant antigens? More studies are needed to answer these questions.

In addition to select peptide specific $\mathrm{T}$ cells, our method provides a platform for protein-specific T cells selection. Protein-specific T cell selection should be feasible even though we did not perform such experiments here. Monocytes can adhere on surface for a few hours before becoming floating cells, while it takes 18-24 hours for them to uptake, process and present the protein antigens. The activated PEG polymer, however, is able to immobilize them onto solid support for $\mathrm{T}$ cell selection. Because majority of the $\mathrm{T}$ cells generated this way are likely CD4+ T cells, additional intervention to promote cross-presentation, e.g. exploiting liposome technology might be needed.

Finally we introduced a novel monocyte and LCL based antigen-specific T cell selection system. Our data demonstrated this new $\mathrm{T}$ cell selection system is superior to traditional repeated stimulation method in generating antigen-specific $\mathrm{T}$ cells. Not only can this novel $\mathrm{T}$ cell selection 
system purify CD8+ antigen-specific T cells, but also select and purify CD4+ antigen-specific T cells (Li et al., 2006). Although the efficacy of T cell selection from both monocyte and LCL based selection systems appears comparable to each other, there are obvious advantages and disadvantages in each selection system. Monocytes are readily available. However purification of monocytes requires additional elutriation after apheresis, which increases cost. In addition, in some heavily chemotherapy-treated cancer patients, cytopenia may preclude monocyte elutriation. In this situation, LCL based T cell selection system would help to solve the problem. In addition, expansion followed by T cell selection with LCL based system generated more cells than monocyte based system. The main disadvantage with LCL is that it requires 3 to 4 weeks to establish adequate amount of transformed B cell lines. Nevertheless, we believe that this novel T cell selection system provides a valuable means to generate high quality antigen-specific $\mathrm{T}$ cells simply, rapidly and inexpensively. More importantly, this novel T cell selection system can work broadly with other antigens as noted above, and is not just limited to EBV related antigens. 


\section{Reference}

Bollard CM, Straathof KC, Huls MH, et al. 2004a. The generation and characterization of LMP2specific CTLs for use as adoptive transfer from patients with relapsed EBV-positive Hodgkin disease. J Immunother. 27:317.

Bollard CM, Aguilar L, Straathof KC, et al. 2004b. Cytotoxic T lymphocyte therapy for EpsteinBarr virus Hodgkin's disease. J Exp Med. 200:1623.

Brooks L, Yao QY et al. 1992. Epstein-Barr virus latent gene transcription in nasopharyngeal carcinoma cells: coexpression of EBNA1, LMP1, and LMP2 transcripts. J Virol. 66:2689.

Bousso P, Levraud JP, Kourilsky P, Abastado JP. 1999. The composition of a primary T cell response is largely determined by the timing of recruitment of individual T cell clones. J. Exp. Med. 189:1591.

Brunner KT, Mauel J, Cerottini JC, Chapuis B. 1968. Quantitative assay of the lytic action of immune lymphoid cells on 51-Cr-labelled allogeneic target cells in vitro; inhibition by isoantibody and by drugs. Immunology. 14:181

Busson P, Edwards RH, Tursz T, et al. 1995. Sequence polymorphism in the Epstein-Barr virus latent membrane protein (LMP)-2 gene. J Gen Virol. 76:139.

Comoli P, Pedrazzoli P, et al. 2005. Cell therapy of stage IV nasopharyngeal carcinoma with autologous Epstein-Barr virus-targeted cytotoxic T lymphocytes. J Clin Oncol. 23:8942

Deacon EM, Pallesen G, Niedobitek G, Crocker J, Brooks L, Rickinson AB, Young LS. 1993. Epstein-Barr virus and Hodgkin's disease: transcriptional analysis of virus latency in the malignant cells. J Exp Med. 177:339.

De Boer RJ, Oprea M, Antia R, Murali-Krishna K, Ahmed R, Perelson AS. 2001. Recruitment times, proliferation, and apoptosis rates during the CD8(+) T-cell response to lymphocytic choriomeningitis virus. J Virol. 75:10663.

Dudley ME, Wunderlich JR, Robbins PF, et al. 2002. Cancer regression and autoimmunity in patients after clonal repopulation with antitumor lymphocytes. Science. 298:850-854.

Fahraeus R, Fu HL et al. 1988. Expression of Epstein-Barr virus-encoded proteins in nasopharyngeal carcinoma. Int J Cancer. 42:329.

Grakoui, A., S.K. Bromley, C. Sumen, et al. 1999. The immunological synapse: a molecular machine controlling $\mathrm{T}$ cell activation. Science 285:221

Grasser FA, Murray PG et al. 1994. Monoclonal antibodies directed against the Epstein-Barr virus-encoded nuclear antigen 1 (EBNA1): immunohistologic detection of EBNA1 in the malignant cells of Hodgkin's disease. Blood. 84:3792.

Gustafsson, A., V. Levitsky, J.Z. Zou, T. Frisan, T. Dalianis, P. Ljungman, O. Ringden, J. Winiarski, I. Ernberg, and M.G. Masucci. 2000. Epstein-Barr virus (EBV) load in bone marrow transplant recipients at risk to develop posttransplant lymphoproliferative disease: prophylactic infusion of EBVspecific cytotoxic T cells. Blood. 95:807. 
Heslop, H.E., C.Y.C. Ng, C. Li, C.A. Smith, S.K. Loftin, R.A. Krance, M.K. Brenner, and C.M. Rooney. 1996. Longterm restoration of immunity against Epstein-Barr virus infection by adoptive transfer of gene-modified virus-specific T lymphocytes. Nat. Med. 2:551.

Hommel M, Kyewski B. 2003. Dynamic changes during the immune response in T cell-antigenpresenting cell clusters isolated from lymph nodes. J Exp Med. 197:269.

Johnson D, Mendicino J, Cormier M, and Travis J. 1974. Fed. Proc 33:1502

Kay G and Lilly MD. 1980. Biochim. Biophys. Acta. 198: 276

Khanim F, Yao QY, Niedobitek G, et al. 1996. Analysis of Epstein-Barr virus gene polymorphisms in normal donors and in virus-associated tumors from different geographic locations. Blood. 88:3491.

Khanna, R., S. Bell, M. Sherritt, A. Galbraith, S.R. Burrows, L. Rafter, B. Clarke, R. Slaughter, M.C. Falk, J. Douglass, et al. 1999. Activation and adoptive transfer of Epstein-Barr virusspecific cytotoxic T cells in solid organ transplant patients with posttransplant lymphoproliferative disease. Proc. Natl. Acad. Sci. USA. 96:10391.

Lee SP, Thomas WA, Murray RJ, et al. 1993. HLA A2.1-restricted cytotoxic T cells recognizing a range of Epstein-Barr virus isolates through a defined epitope in latent membrane protein LMP2. J Virol. 67:7428.

Lee SP, Brooks JM, Al Jarrah H, et al. 2004. CD8 T cell recognition of endogenously expressed Epstein-Barr virus nuclear antigen 1. J Exp Med. 199:1409.

Levitskaya J, Coram M, Levitsky V, et al. 1995. Inhibition of antigen processing by the internal repeat region of the Epstein-Barr virus nuclear antigen-1. Nature. 375: 685.

Lezzi G, Karjalainen K, Lanzavecchia A. 1998. The Duration of Antigenic Stimulation Determines the Fate of Naive and Effector T Cells. Immunity. 8: 89.

Li J, Melenhorst J, Hensel N, Rezvani K, et al. 2006. T cell responses to peptide fragments of the BKV T antigen - implications for cross-reactivity of immune response to JC virus. J Gen Virol 87: 2951.

Li J, Mookerjee B, Wagner J. 2007. Purification of melanoma reactive T cell by using a monocyte-based solid phase $\mathrm{T}$ cell selection system for adoptive therapy. J. Immunotherapy. In press

Mackensen A, Meidenbauer N, Vogl S, et al. 2006. Journal of Clinical Oncology. 24:5060

Merrifield, RB. 1963. J. Am. Chem. Soc. 85, 2149

Monks, C.R., B.A. Freiberg, H. Kupfer, et al. 1998. Three-dimensional segregation of supramolecular activation clusters in T cells. Nature. 395:82.

Mur VI. Russ. 1964. Chem. Rev. 33:92 
Niedobitek G, Kremmer E, Herbst H, Whitehead L, Dawson CW, Niedobitek E, von Ostau C, Rooney N, Grasser FA, Young LS. 1997. Immunohistochemical detection of the Epstein-Barr virus-encoded latent membrane protein 2A in Hodgkin's disease and infectious mononucleosis. Blood. 90:1664.

Pallesen G, Hamilton-Dutoit SJ, Rowe M, Young LS. 1991. Expression of Epstein-Barr virus latent gene products in tumour cells of Hodgkin's disease. Lancet. 337:320.

Rooney, C.M., C.A. Smith, C. Ng, S.K. Loftin, C. Li, R.A. Krance, M.K. Brenner, and H.E. Heslop. 1995. Use of genemodified virus-specific T lymphocytes to control Epstein-Barr virusrelated lymphoproliferation. Lancet. 345:9.

Rooney, C.M., C.A. Smith, C.Y.C. Ng, S.K. Loftin, J.W. Sixbey, Y.-J. Gan, D.-K. Srivastava, L.C. Bowman, R.A. Krance, M.K. Brenner, and H.E. Heslop. 1998. Infusion of cytotoxic T cells for the prevention and treatment of Epstein-Barr virus-induced lymphoma in allogeneic transplant recipients. Blood. 92:1549.

Sing AP, Ambinder RF, Hong DJ, et al. 1997. Isolation of Epstein-Barr virus (EBV)-specific cytotoxic T lymphocytes that lyse Reed-Sternberg cells: Implications for immune-mediated therapy of EBV Hodgkin's disease. Blood. 89:1978.

Straathof KC, Bollard CM, et al. 2005. Treatment of nasopharyngeal carcinoma with EpsteinBarr virus--specific T lymphocytes. Blood. 105:1898.

Tellam J, Connolly G, Green KJ, et al. 2004. Endogenous presentation of CD8+ T cell epitopes from Epstein-Barr virus-encoded nuclear antigen 1. J Exp Med. 199:1421.

Topalian SL, Muul LM, Solomon D, Rosenberg SA. 1987. Expansion of human tumor infiltrating lymphocytes for use in immunotherapy trials. Journal of Immunological Methods. 102:127-141.

Trivedi P, Hu LF, Christensson B, et al. 1994. Epstein-Barr virus (EBV)-encoded membrane protein LMP1 from a nasopharyngeal carcinoma is non-immunogenic in a murine model system, in contrast to a B cell derived homologue. Eur J Cancer. 30A:84.

Voo KS, Fu T, Wang HY et al. 2004. Evidence for the Presentation of Major Histocompatibility Complex Class I-restricted Epstein-Barr Virus Nuclear Antigen 1 Peptides to CD8_T Lymphocytes. J Exp Med. 199:459.

Whitney BM, Chan ATC, Rickinson AB, et al. 2002. Frequency of Epstein-Barr virus-specific cytotoxic T lymphocytes in the blood of Southern Chinese blood donors and nasopharyngeal carcinoma patients. J Med Virol 67:359

Yee C, Thompson JA, Byrd D, et al. 2002. Adoptive T cell therapy using antigen-specific CD8+ $\mathrm{T}$ cell clones for the treatment of patients with metastatic melanoma: In vivo persistence, migration, and antitumor effect of transferred T cells. Proc Natl Acad Sci U S A 2002, 99:16168-16173

Young LS, Dawson CW, Clark D, Rupani H, Busson P, Tursz T, Johnson A, Rickinson AB. 1988. Epstein-Barr virus gene expression in nasopharyngeal carcinoma. J Gen Virol. 69:1051. 


\section{Footnote:}

The authors have no commercial or other association that might pose a conflict of interest.

Financial support: Department of Health, Pennsylvania

Address correspondence and reprint requests to Dr. Jongming Li, Department of Medical Oncology, 1024 Curtis Building, Thomas Jefferson University, 1015 Walnut St., Philadelphia, PA, USA 19107. E-mail address: jongming.li@jefferson.edu. Telephone: 215 9553973. Fax: 215 9230797

$\begin{array}{ll}\text { Abbreviations used in this paper: } & \\ \text { EBV-associated post-transplant lymphoproliferative diseases } & \text { PTLD } \\ \text { Hodgkin lymphoma } & \text { HL } \\ \text { Nasopharyngeal carcinoma } & \text { NPC } \\ \text { Adoptive cell transfer } & \text { ACT } \\ \text { Dendritic cells } & \text { DC } \\ \text { Normal AB serum } & \text { NABS } \\ \text { Recombinant human IL-2 } & \text { rhIL-2 } \\ \text { Flow cytometric intracellular cytokine assay } & \text { ICC } \\ 10 \% \text { normal AB serum/RPMI-1640 } & \text { CM } \\ \text { EBV transformed B lymphocyte } & \text { LCL }\end{array}$




\section{Figure Legends}

Figure 1. Solid phase T cell selection. PBMC was activated by autologous irradiated LCL. LCL was immobilized on the glass. Activated lymphocytes were added, selected at various times and non-adherent cells were then removed by washing.

Figure 2. Selection of EBV-specific T cell by immobilized LCL (Donor 1)

A). Representative dot plots of 3 similar experiment results of $\mathrm{T}$ cell selection: the numbers in the upper right quadrants represent percent $\mathrm{EBV}$-specific $\mathrm{CD} 8+\mathrm{T}$ cells within gated CD3+ cells on the support surface after selection. Selection times are indicated above the frame of dot plots. Data of T cells selected at 1,10 and 15 minutes were not shown. B). Lymphocytes of Figure 2A were expanded after selection. The numbers in the upper right quadrants represent percent EBV-specific CD8+ T cells within gated CD3+ cells. Selection times are indicated above the frame of dot plots. Representative dot plots of 3 similar experiment results of 3 and 5 minutes selection were shown. Data of expanded T cells selected at 10 and 15 minutes were not shown. C). Of lymphocytes shown in Figure 2B, LMP2 (LLW, CLG \& FLY)-specific T cells were measured as percent (mean, \pm SD) IFN- $\gamma+\mathrm{CD} 8+\mathrm{T}$ cells within gated CD3+ cells. The numbers in the upper right quadrants represent percent LMP2 (LLW, CLG \& FLY)-specific CD8+ T cells within gated CD3+ cells. Selection times are indicated above the frame of dot plots. Representative dot plots of 3 similar experiment results of 3 and 5 minutes selection were shown. Data of expanded T cells selected at 10 and 15 minutes were not shown. D). EBV-specific T cells were measured as percent (mean, \pm SD) IFN- $\gamma+$ positive CD8+ T cells within gated CD3+ T cells on day 0, 1, 2 and 7 after selection. E). Lymphocytes generated from various selection times lyse autologous LCL, whereas there is no significant percent lysis of K562 and LCL when MHC I antibody (w6/32) was added to the latter (cytotoxicity data from 5 minutes selection $\mathrm{T}$ cells were shown as representative). Each point represents the mean of data from triplicate experiments.

Figure 3. LMP2-specific T cell selection with immobilized LCL (donor 5). A). Representative dot plots of 3 similar experiment results of CLG-specific T cell selection: the numbers in the upper right quadrants represent percent CLG-specific CD8+ T cells within gated CD3+ cells on the support surface after selection. Selection times are indicated above the frame of dot plots. Data of T cells selected at 3 and 15 minutes were not shown. B). Lymphocytes of Figure 3A were expanded after selection (7.5 minutes). Representative dot plots of ICC and tetramer assay of 3 similar experiment results were shown: the numbers in the upper right quadrants represent percent CLGspecific CD8+ T cells within gated CD3+ cells. Selection times are indicated above the frame of dot plots of ICC and tetramer assay. C). CLG-specific T cells generated by CLG-pulsed-LCL selection lyse T2 cell line pulsed with CLG and do not have significant killings of T2 cell line pulsed with CMV pp64 peptide $\mathrm{P}_{495-503}$. Each point represents the mean of data from triplicate experiments. 
Figure 4. LMP2-specific T cell selection with immobilized monocytes (donor 5). A). Representative dot plots of 3 similar experiment results of CLG-specific T cell selection: the numbers in the upper right quadrants represent percent CLG-specific CD8+ $\mathrm{T}$ cells within gated CD3+ cells on the support surface after selection. Selection times are indicated above the frame of dot plots. Data of T cells selected at 1 and 3 minutes were not shown. B). Lymphocytes of Figure 4A were expanded after selection (7.5 minutes). Representative dot plots of ICC and tetramer assay of 3 similar experiment results were shown: the numbers in the upper right quadrants represent percent CLGspecific CD8+ T cells within gated CD3+ cells. Selection times are indicated above the frame of dot plots of ICC and tetramer assay. C). CLG-specific T cells generated by CLG-loaded-monocytes selection lyse T2 cell line pulsed with CLG and do not have significant killings of T2 cell line pulsed with CMV pp64 peptide $\mathrm{P}_{495-503}$. Each point represents the mean of data from triplicate experiments. 